\title{
"BUT HOW CAN I ACHIEVE MY DREAM IN THIS VILLAGE?" BLEAK EDUCATIONAL HOPES AND ASPIRATIONS OF CHILDREN IN AGORTIKOPE VILLAGE
}

\author{
Eunice Abbey and Judith Kafui Darkey \\ Department of Social Work, Faculty of Social Sciences, University of Ghana, P.O. Box LG 419, Legon-Accra, Ghana
}

Received 2013-09-28, Revised 2013-09-30; Accepted 2013-11-01

\begin{abstract}
This was a study conducted to identify the challenges that children in rural areas encounter in education. Most of these challenges affect the educational aspirations and dreams of these children. These issues were explored in group and in-depth interviews with the children, parents and teachers at Agortikope village. Some of the major issues discovered centered on financial difficulties, inadequate learning and teaching materials, poor infrastructure, teacher absenteeism, amongst others. The Human Capital theory which stresses the significance of education and training as the key to development and participation in the new global economy guided the study. The participants for the study were 17. About 12 pupils from classes 4 to 6 and 2 teachers, 2 parents of the participants and the headmaster of the school. The studies revealed one major thing; that these children have dreams, goals and aspirations but are also uncertain of achieving them because of all the challenges that they face.
\end{abstract}

Keywords: Bleak, Educational Aspirations, Rural Communities, Children

\section{INTRODUCTION}

The importance and quality of education has become a major strategy around the globe to achieve greater development. Apart from the enormous benefits a country derive from equipping its populace with quality education, children are also offered with skills and tools to deal with different roles when they grow up. Education helps in the development of the individual personality. Education is "a fundamental human right. It is the key to sustainable development, peace and stability within and among countries. Education is an important aspiration of individuals and a basic need. It does not only have a strong impact on well-being but also, on future jobs and wages. Individuals who are better educated are equiped to participate more actively in politics in the society and rely less on social assistance (OECD, 2011).

The 2000 Dakar framework for action postulates that more than 113 million children have no access to primary education and 880 million adults are illiterate. Indeed, education forms the building block of every nation's economic social and political development. Education at large helps in transmitting the values, beliefs and knowledge of society. In a more formal way, the Merriam Webster's dictionary defines education as the "field of study that deals mainly with methods of teaching and learning in schools".

Whilst most developed countries have achieved a lot with respect to quality education, the case is very different in developing and poor countries. Ghana is no exception to this. Over the past years, efforts have been made by the government of Ghana to enhance education and its quality. Some of these included the extensive distribution of free school uniforms and free exercise books across the country in 2009. Again 3,470 schools under trees were relocated into 3,470 three classroom and six classroom blocks. The school feeding program also underwent radical and limitless P.O. Box LG 419, Legon-Accra, Ghana 
expansion (Hayford, 2011). The situation is even worst in rural and deprived areas of Ghana.

Rural areas in Ghana are generally seen as places where they lack basic and social amenities like water, schools, clinics, electricity. Children in such areas often lack the basic amenities and support for their education. Many are therefore likely to drop out of school leaving their educational dreams unachieved. Others may also become candidates of deviant behaviors and a burden on society and the country as a whole.Often plagued by several problems, the quality of education and learning fall far short of the dreams and aspirations of children in the villages of Ghana. What are the reasons for poor quality education for children in these rural areas? Are these children hopeful in achieving their dreams under these circumstances? The study aims to contribute to understanding these questions and present the results from group interviews with children in Agortikope village as a case study.

\subsection{Research Questions}

- What are the reasons for poor quality education for children in these rural areas?

- Are these children hopeful in achieving their dreams in these circumstances?

\subsection{Theory and Literature Review}

The Human Capital theory is based on the assumption that formal education is an important instrument to improve the capacity of a population. It basically involves the investment in training and education (OECD, 2010). Human capital deals with accumulating investments into labour force. To this end, education is the most important sort of human capital (Soukup and Sredl, 2009). The theory generally represents the assets each individual develops to enhance economic productivity. In this regard, the individual also benefits by gaining economic success and achievement. Thus, investing in human capital is necessary to encourage people to develop entirely new ideas, products, processes and methods through creative approaches; giving individuals the appropriate parts of the knowledge which has already been accumulated by previous generations and how existing knowledge should be used to develop new products, to introduce new processes and production methods and social services (Almendarez, 2001).

In relating the theoryto the study, turning the children of Agortikope into productive adults in the future depends on how much investment is made in their formal education. It will also depend on the kind of training and knowledge they receive at schools and the necessary tools provided to fulfill their dreams.

A lot of studies have been done on the quality of education for children in deprived areas of Ghana. Some of the findings indicated that Lack of educational resources, financial difficulties, teacher absenteeism, quality of teacher, lack of supervision,pupil-teacher ratios among others accounted for low quality education in rural Ghana. Few of these are outlined below.

Adamu-Issah et al. (2007), on Achieving Universal Primary Education in Ghana by 2015 indicates that though enrolment has increased at all levels of education in Ghana, enrolment at the primary level is still very low. There are still some parts of Ghana where access to basic education is lower and persistently underserved. For instance, the Northern Region of Ghana has persistently reported lower school attendance rates than the national average. Again, the rural and deprived districts are worse off when it comes to the availability and deployment of teachers. A teacher was expected to handle as many as 100 or more pupils in most of these deprived areas (Adamu-Issah et al., 2007).

Aheto-Tsegah (2011), on Education in Ghana; Status and Challenges asserted that the distribution of teachers continues to be a disadvantage in rural areas. With regards to trained teachers, it is even worse. According to him, the percentage of trained teachers at the basic level is very low. For instance, only 51 and $66 \%$ of trained teachers are found in the Primary and Junior High School levels respectively (Aheto-Tsegah, 2011).

In addition to the above, children are likely to drop out of school due to low attendance, low attainment and grade repetition. These factors combine with others like socio-economic, household and context specific features which determine whether a child will remain in school or not. Thus, the child stands the risk of leaving school before completing a cycle of basic education (Akyeampong et al., 2007).

In a study conducted by Estey et al. (2009), on the Review of Basic Education Quality in Ghana in North Dayi District (Volta Region), the findings indicated that the lack of infrastructure and resources were responsible for the poor academic performance of students in the area. The study also revealed that teacher morale was a major problem in most schools in the area. Increasing teacher morale and motivating them will change their negative attitudes towards teaching and thereby, promote quality education in the area.

In another study by Ankomah et al. (2005), on implementing quality education in low income countries; 
Literature Review, Ghana, showed that financial constraints on the part of government in enforcing educational policies and initiatives and parents' inability to support their children's education reduces the quality of education. Also teacher quality and absenteeism were seen as critical indicators of quality education. The quality of training teachers receive, the academic qualification and years of service are key in promoting quality education in Ghana. Teacher absenteeism on the other hand, reduces quality education and results in waste of resources (Ankomah et al., 2005).

\subsection{The Context (Agortikope)}

Agortikope is located around the outskirts of Amansanin the Ga East District of the Greater Accra Region of Ghana. Though located in Ga East, the residents are mostly migrant farmers who are Ewes. Thus the main occupation of the people of Agortikope is farming with a few people engaged in petty trading. The language commonly spoken is Ewe. Communal living is one of the virtues in Agortikope and reflects in their social, economic and religious activities. The highest level of authority is the chief who oversees all affairs in the village. The main means of transportation within the village as well as between the village and other surrounding villages is by foot. However, few motor bikes and cars are resorted to periodically whenever available for transportation outside the village. The only school in the village is the Agortikope MA Primary School which provides basic education to the children within the village and those from surrounding villages.

\section{MATERIALS AND METHODS}

\subsection{Participants}

The research design adopted for the study is qualitative. The researchers took a phenomenological approach. A phenomenological approach "identifies the essence of human experiences about a phenomenon as described by the participants" (Creswell, 2009). This enabled the researchersto identify and gain an indepth knowledge in the challenges that children of Agortikope encounter in education. By this, the researchers had the opportunity to understand the lived experiences of the participants.

The data was collected through a Focus Group Discussion and in-depth interviews. The groups consisted of children from classes 4 to 6 . A total number of 12 pupils between the ages of 13-17 were interviewed. 6 females and 6 males were picked from classes 4-6, 2 from each of the classes. 2 teachers and the headmaster of the school were also interviewed as well as 2 parents of the participants that were selected. Thus a total of 17 participants were used for this qualitative study. The pupils were interviewed at the school premises and felt comfortable to do a Focus Group Discussion. However, the in-depth interviews were conducted for the 2 teachers, the headmaster and the 2 parents that were selected for the study.

\subsection{Sample Design and Recruiting Participants}

The sampling design used for this study was purposive. This is based on the premise that participants who possess the characteristics, roles, opinions, knowledge, ideas or experiences that are particularly relevant to the study are selected (Creswell, 2009). Using a purposive sampling design enabled the researchers to explain the study, its purpose and inclusion criteria to the teachers in the school. By this, the teachers were guided by the researcher to use their knowledge of the study area and the school to choose the participants. The teachers used the class register which contained the names and dates of birth of the pupils in the selection process. Those who fell within the age range of 13-17 years were then selected.

\subsection{Data Collection Procedure}

A semi-structured interview guide was developed to gather data from the participants. About 2 Focus Group Discussions (FGD) were held for the pupils. Each of the FGD ended for about $45 \mathrm{~min}$. However, the in-depth interviews with the teachers and parents lasted for 35 min. All the 6 females were put in a single group and the 6 males were put in another group. This was so because the researchers assumed that the females may be shy sitting in a group discussion with the males. The teachers in the school at the time of the data collection confirmed this assumption. The first FGD with the females was organized in class 1 and that with the males was done in class 2 . The discussions were done at different times. The in depth interviews with the teachers and parentswere later done in the day. The teachers were interviewed in their classrooms and the parents, in their homes. All the interviews and discussion were audio taped and notes were taken throughout the data collection procedure.

\subsection{Transcription}

The interviews were performed in both the English and Ewe languages. Being an Ewe-dominated village, the pupils expressed themselves well in the Ewe language. There was no need for a translator as one of 
the researchers speaks and understands the Ewe language very well. One of the researchers made an audio-recording of the interviews and the other took extensive notes on the context and general atmosphere during the interview. The interviews conducted in Ewe were later transcribed and translated into English by one of the researchers. This gave the researchers an upper hand over the data. Data collected from the discussions and interviews were compared to what the researchers observed in the village to check for their consistencies. By observation, the researchers were able to gain an insider understanding of the challenges the participants faced in Agortikope.

\subsection{Data Analysis}

The data was analyzed using Attride-Sterling (2011) steps in qualitative data analysis. The recorded interviews were first played and listened to several times by the researchers. This helped in dissecting the information into manageable and meaningful text segments and codes. A sheet was then prepared for each of the interviews and the FGD organized. The codes generated were then labeled against the appropriate themes on the sheets that were prepared. This was carefully done by taking into consideration the objectives of the study. Lastly, the themes were related to the research objectives to explore the challenges that pupils of Agortikope face and the implications on their aspirations.

\subsection{Ethical Considerations}

The pupils are all minors hence permission was sought from parents of the selected participants before they were interviewed. The Principal of the school and class teachers of the participants also gave consent on behalf of the participants before the focus group discussion begun.

The pupils were also allowed to choose the place of the interview on their own. All of them felt comfortable being interviewed in the school premises as compared to their homes. Some of them gave reasons that the presence of their parents may influence what they would want to tell the researchers.

The pupils were at will to opt out of the discussion session at any given time and were free not to answer questions they thought will make them uncomfortable.All the participants were given pseudonyms in order to hide their identities except the headmaster of the school who did not have any problem with his identity.

\section{RESULTS}

The participants' information on the challenges of poor quality education in the area and the implications for the pupils' dreams and aspirations were centered on major issues financial difficulties, long distance to school, inadequate educational facilities, teacher quality, lack of supervision and pupil-teacher ratio.

\subsection{Financial Difficulties}

The pupils stated that their parents are unable to give them money to pay for exercise books and stationery. Their school fees are not paidhence; they are often sacked from school. Some of the pupils miss classes because they are not given money to buy food at school. Also, the pupils claimed they feel shy in going to school in tattered uniforms as their parents do not have money to buy them new ones. This resulted in not taking part in terminal exams and class assignments and sometimes, repeating a class. The parents also stated that they do not have sufficient money to cater for their children. This was due to low income generating activities and unemployment in general. These were some of the affirmations:

"I am not a happy woman, I wish to take my children far in school but I am helpless. I am a petty trader and I don't get enough money from this. All the money I get goes into feeding...I can't starve them and use the money to buy books." Abla.

"I do not have exercise books and pen to use in class because my father said he has no money. I lose a lot of marks since I do not take part in class assignments." Kofiga.

"The headmaster always sacks me for school fees. I should have been in class 5 by now but I was repeated in class 4 for a year."(Pemba).

"I am only a farmer and I don't make enough money when I sell my farm yields so it's difficult taking care of my 3 children.” Papa Ga.

\subsection{Long Distance}

Most of the pupils complained they do not like going to school because they have to walk for longer hours before they got to school. The situation was same for some of the teachers. For the pupils, they often arrive late and are punished by the teachers. They complained of getting tired when they arrive in class and often fell asleep. According to them, they preferred to follow their parents to the farm than walk that long to school:

"I wake up very early around 4am to go to school. My house is too far and I always come to school late. Sometimes, I return to the house because I do not want to be punished." Adzovi. 
"I have been nicknamed "the late comer" because I am always late to school. By the time I get to class, they have already learnt a lot and I do not take part in class texts." Sly.

"I live in the outskirts of the town. As a teacher, it is very difficult for me to walk to the school every day. It is just too far... when it rains, the pathways become flooded and I just stay at home." Sir Peter.

\subsection{Inadequate Educational Facilities}

The teachers interviewed complained of inadequate educational facilities. They stated that the school lacks a lot of teaching and learning materials such as text books. Most of the times, three pupils must share a textbook during teaching hours. They remarked that they were unable to give home work to the pupils as they do not know how the textbooks could be given out because the pupils live at different locations. There were also no storage facilities for Teaching and Learning Materials (TLM). The teachers had to carry the materials home which was tiring to do each day. The school had no library where pupils could go to do additional learning and studies.

The researchers observed that the school building was almost falling apart. Most of the classrooms had no windows and doors, the roofs had leakages exposing pupils to extreme weather conditions. The furniture was not enough to accommodate all the pupils. Whilst most of them shared tables and chairs, a few sat on the floor:

\begin{abstract}
"We the teachers who are placed in rural areas suffer a lot. We do not have access to computers and we do not even have the teaching materials. How can we do our job?.” Madam Sapa.

"Look at the chair I sit on teach, it's almost broken. The school structure is very bad and when it rains no one shows up for school. Sometimes, I come to sit here for hours with no student to teach." UK.
\end{abstract}

\subsection{Teacher Quality}

According to the teachers in the school, most of the qualified teachers refuse postings to the rural areas because they are not conducive enough to suit their interests and goals. Consequently, only few end up teaching in deprived areas. In the case of Agortikope Primary School, out of the 5 teachers in the school, only 2 were trained teachers including the headmaster. The rest were senior high school graduates. The headmaster stated the school had no choice as the Ghana Education service had not posted any teachers to the area. The school had to make do with the SHS graduates:

"I completed senior secondary school last year. I come from this village and I decided to help because the school do not have enough teachers." Biggie.

"The situation is very bad here. Giving quality education to these kids depends on the background of the teachers. As you can see, most of the teachers here are not trained and I worry a lot as the head of this school the kind of teachings they receive." Headmaster.

\subsection{Lack of Supervision}

The headmaster who also acted as a teacher in school was of the view the school lacks proper supervision from the Ghana Education Service (GES). They hardly receive any official in the school to monitor and supervise the teacher's work as well as to know the challenges that the school had. This has had a negative impact on the attitudes of the teachers. Some of the teachers did not goto school often and when they did, they were often late:

"As the head of this school, I can say that I do a lot of work than I am supposed to. I teach as well as to ensure that everything goes on well in the school but I do not have absolute control on the teachers because the conditions here are bad. It would help a lot if the officials visit the school often." Headmaster.

"My sister you cannot blame us. I have been teaching in this school for the past 6 years but I have nothing to show for this. My salary will not come on time and sometimes I have to use my money to buy books for some of the poor pupils. It is sad because I know most of my colleagues are enjoying in the cities." Sir Peter.

\subsection{Pupil-Teacher Ratio}

The teachers interviewed said they are not many and each teacher has to handle a class of about 50-60 pupils and to teach all the subjects. The researchers observed the each class that was visited had only one teacher who was responsible for teaching all the subjects. This places a lot of burden on the teachers and does not give them the opportunity to pay attention to students with special needs. Also, the teachers had no choice than to take the pupils through all the subjects whether they had the adequate knowledge in them or not. The school for the 
past 15 years has performed poorly in the Basic Education Certificate Examination (B.E.C.E). Most of the pupils were not able to further their education and their educational dreams ended at the primary level:

"I get tired a lot. I teach all the subjects and I am responsible for marking and conducting exams for the pupils. They are many...how canone person do all these." Madam Sapa

"We really need help in this school. It is as if we do not exist in Ghana. The government must pay attention to schools in areas like this and send more people here to teach. What will happen if we also decide to leave?." Headmaster.

"In fact, I am looking for other opportunities somewhere and if I get it I will leave. I am just tired of this school." Sir Peter

\subsection{Are These Children Hopeful in Achieving their Dreams?}

The information given by the pupils indicated that most of them had no hope of achieving their dreams in the future. It was obvious that conditions around them, both at school and in their homes did not encourage them to fulfill their dreams in the future. When the researchers asked the pupils of their future ambitions, most of them had big dreams of becoming doctors, teachers and lawyers but worried because their parents told them they had no money. Instead, they had chosen to follow the paths of their parents to become farmers, hairdressers and stone crackers. They said they had no one to support or encourage them. One of them said something that touched the heart of the researchers hence the topic of this study; "I love the doctors when i see them on television. I want to be like them but how can I achieve my dream in this village?" The researchers felt like they had to give an assuring answer to the question the small boy posed. The rest had the following to say:

"My parents always tell me they do not have money to send me to school after primary. I told them I want to be a teacher but I now have to learn carpentry from my uncle during the weekends." Fokwame.

"My mother told me a girl is not supposed to go to school for long because of marriage. I have decided to stop school if I repeat again and go to learn a trade." Bene.

"I want to study hard to become an engineer. I do not know if I can do this because my family has no money. My parents struggle a lot to even pay my school fees." Aziz.
"I have to help my mother sell in the market so I do not come to school at times. If I do not help her, I won't get money to school (She sobs). I wonder if I can do anything else apart from this" Mercy.

\section{DISCUSSION}

From the above, it is obvious that schools like Agortikope in deprived areas of Ghanaencounter a lot of challenges that prevent the transmission of quality education to pupils. These challenges may be similar to other schools in the same District. The findings indicated that not much was invested in the formal education of children in such areas. As part of the human population, this has serious implications for the development of the country as a whole.Financial difficulties and parents' inability to support the education seem to be major factors hindering the quality of education in Agortikope. This supports Ankomah et al. (2005) findings from the study on implementing quality education in low income countries; Literature Review- Ghana.

Closely linked to the above are the absence or inadequate teaching and learning materials and poor school infrastructure. The ability to achieve these depends on a lot of financial sacrifice on the part of government in these areas. As noted well by Estey et al. (2009), on the Review of Basic Education Quality in Ghana in North Dayi District (Volta Region), the findings indicated that the lack of infrastructure and resources were responsible for the poor academic performance of students in the area. Just like teacher morale was an issue in Agortikope, the same was true in Estey et al. (2009) findings in the Volta Region of Ghana. Motivating and increasing teacher morale and will change their negative attitudes towards teaching and thereby, promote quality education in poor areas like Agortikope.The quality of teachers in Agortikope Primary School is very low. This is also a common situation in most deprived areas in Ghana where similar studies have been done. For instance, in Aheto-Tsegah (2011) findings on the Status and Challenges of Education in Ghana, trained teachers hardly accepted postings to poor rural areas. Sometimes, there were no teachers at all. In the case of Agortikope, Senior High School Graduates had to take up teaching roles in the school though they did not have the training and qualification to do so. There is no denying the fact that the future of children in poor rural areas largely depends on the efforts of their teachers as well.It is therefore imperative to pay attention to the teachers in these areas. 
One of the issues that cannot be ignored is the pupilteacher ratio.A teacher in Agortikope had to take a class of about 50-60 pupils against the national average of 43 pupils at the primary school level. The Ghana Poverty Reduction Strategy Report of 2002 indicated that pupilteacher ratio is a major problem in poor rural areas of Ghana especially in the Northern Region. According to the Report, most of the schools in the Region exceeded the national average pupil-teacher ratio of 43 .

Judging from the above challenges in Agortikope primary school, the pupils are unlikely to realize their dreams and aspirations since they may not be able to further their education. To them, the ability to achieve their future aspirations is closely linked to the kind of education they receive in the village. Not achieving their aspirations also implies that the nation will lose the contributions that they couldhave made to national development in the future. The children also stand the risk of becoming social misfits. They may be forced to engage in all sorts of unacceptable behaviors like stealing, prostitution, drugs abuse and trafficking to make ends meet. In this regard, theybecome a social burden on society, a liability instead of an asset.

\section{CONCLUSION}

It can be concluded that the future of pupils in Agortikope is highly dependent on making more investments in their education as well as in the teachers who educate them. In order to make things better and give hope to the children, a lot of changes must be made in their environment. Parents must show more concern and sacrifice to invest in the education of their children. The findings of the study also call for adopting comprehensive policies of education and development that will cover all rural communities in the country. More financial capital should be pushed into the education sector. At the time of the study the pupils in Agortikope were happy and keen to learn but were also unsure of achieving their dreams looking at the challenges they faced. The Ghana Education Service will also have to pay attention to schools in the deprived areas and ensure that learning and teaching materials are available for all. The government of Ghana could put in place attractive incentives for teachers who accept postings to rural areas.

Time constraints could not allow the researchers to cover other villages in the District. It will help in future studies if a similar study is done on a larger scale to cover not only rural areas in Ghana but other African countries. With regards to educational aspirations, a comparative study for children in rural and urban areas will be an interesting thing to look at. It will also draw out more specific guidelines to achieving quality education for all children. The call to achieving quality education in society is a responsibility for all. Research Institutions, Teachers, Governments and the society as a whole has a role to play towards this course.

\section{REFERENCES}

Adamu-Issah, M., L. Elden, M. Forson and T. Schrofer, 2007. Achieving universal primary education in Ghana by 2015: A reality or a dream? United Nations Children's Fund, New York.

Aheto-Tsegah, C., 2011. Education in Ghana-Status and challenges. Commonwealth Education Partnerships.

Akyeampong, K., J. Djangmah, A. Oduro, A. Seidu and F. Hunt, 2007. Access to basic education in Ghana: The evidence and the issues. Consortium for Research on Educational Access.

Almendarez, L., 2001. Human Capital Theory: Implications for educational development. Proceedings of the Belize Country Conference, Nov 21-24.

Ankomah, Y., J. Koomson, R. Bonsu and G.K.T. Oduro, 2005. Implementing quality education in low income countries. University of Cape Coast, Ghana.

Attride-Sterling, J., 2011. Thematic networks: An analytic tool for qualitative research. Q. Res., 1: 385-404. DOI: 10.1177/146879410100100307

Creswell, J.W., 2009. Research Design: Qualitative, Quantitative and Mixed Methods Approaches. 1st Edn., Sage Publication, Los Angeles, ISBN-10: 1412965578, pp: 260.

Estey, K., T.M. Smith, E. Gyamera, J. Koka and J. Boer et al., 2009. Review of basic education quality in Ghana. USAID.

Hayford, E.K., 2011. Two years of better Ghana agenda. Ghana News Link.

OECD, 2010. Social Capital, Human Capital and Health: What is the evidence? Centre for Educational Research and Innovation.

OECD, 2011. Compendium of OECD well-being indicators. OCED. www.oecd.org/std/47917288.pdf

Soukup, A. and K. Sredl, 2009. Various concepts of human capital in process of education. Efficiency Responsib. Educ. Sci., 2: 13-19. 